\title{
qPCR-based relative quantification of the brown algal endophyte Laminarionema elsbetiae in Saccharina latissima: variation and dynamics of host-endophyte interactions
}

\author{
Miriam Bernard $^{1}$ (D) Sylvie Rousvoal ${ }^{1} \cdot$ Bertrand Jacquemin $^{2,3} \cdot$ Marion Ballenghien $^{2} \cdot$ Akira F. Peters $^{4} \cdot$ \\ Catherine Leblanc ${ }^{1}$
}

Received: 12 July 2017 / Revised and accepted: 6 December 2017 / Published online: 19 December 2017

(C) The Author(s) 2017. This article is an open access publication

\begin{abstract}
Morphological changes-such as dark spots, twisted stipes and deformed blades-have been observed in wild and cultivated Saccharina latissima. The putative cause for the disease symptoms is the filamentous endophytic brown alga Laminarionema elsbetiae, which is known to invade stipes and fronds of its hosts. Little is known about this interaction and its occurrence in the field, although former studies indicated high endophyte prevalence in kelp populations. Previous epidemiological studies on kelp endophytes were mainly based on the examination of microscopic sections, followed by time-consuming isolation and cultivation steps in order to identify the endophyte and a reliable method to quantify endophyte infections was missing. As a novel approach, we established and validated a qPCR assay for relative quantification of the endophyte L. elsbetiae within its host S. latissima, which allows to examine both, the prevalence of endophytic algae and the severity of infections. The assay was shown to be highly specific and suitable to reliably detect small amounts of endophyte DNA in the host. Using this method, we detected very high endophyte prevalence in the investigated kelp populations, up to $100 \%$ in young S. latissima sporophytes in Brittany during spring. Furthermore, our results suggest that Saccharina sporophytes are infected early in their life and that seasonality and environmental factors have a significant impact on infection rates. In the future, this approach could also be applied to study other hostendophyte pairs using specific primers.
\end{abstract}

Keywords Endophytes $\cdot$ Laminarionema elsbetiae $\cdot$ Kelps $\cdot$ Saccharina latissima $\cdot$ Quantitative PCR

Electronic supplementary material The online version of this article (https://doi.org/10.1007/s10811-017-1367-0) contains supplementary material, which is available to authorized users.

Miriam Bernard

miriam.bernard@sb-roscoff.fr

Catherine Leblanc

catherine.leblanc@sb-roscoff.fr

1 CNRS, UMR 8227, Integrative Biology of Marine Models, Station Biologique de Roscoff, Sorbonne Universités, UPMC Univ. Paris 06, 29680 Roscoff, France

2 CNRS, UMI 3614, Evolutionary Biology and Ecology of Algae, Station Biologique de Roscoff, Sorbonne Universités, UPMC Univ. Paris 06, 29680 Roscoff, France

3 Present address: CEVA, 22610 Pleubian, France

4 Bezhin Rosko, 29250 Santec, France

\section{Introduction}

The sugar kelp Saccharina latissima (Laminariales, Phaeophyceae) is an important primary producer in temperate to cold northern hemisphere coastal ecosystems (Bartsch et al. 2008) and an economically relevant seaweed with high industrial potential (Østgaard et al. 1993; Adams et al. 2009). Growing or being cultivated in the sea S. latissima is exposed to a high number of potentially harmful organisms such as fungi, bacteria or endophytic algae (Andrews 1977; Wu et al. 1983; Apt 1988a; Potin et al. 2002). Previous studies on the latter reported a high prevalence of filamentous endophytic algae in kelp populations, with up to $100 \%$ of infected individuals (Andrews 1977; Lein et al. 1991; Peters and Schaffelke 1996; Schaffelke et al. 1996; Ellertsdóttir and Peters 1997). Amongst them is Laminarionema elsbetiae 
(Ectocarpales, Phaeophyceae), a filamentous brown algal endophyte highly prevalent in European wild S. latissima populations (Peters and Ellertsdóttir 1996; Ellertsdóttir and Peters 1997). It invades stipes and fronds of its host, thereby potentially not only causing morphological changes but even more severe impairment as it has been shown for other filamentous endophytic brown algae (Yoshida and Akiyama 1979; Apt 1988a, b; Peters and Schaffelke 1996; Ellertsdóttir and Peters 1997; Thomas et al. 2009). Despite an increasing interest in this topic due to the economic importance of Saccharina aquaculture (Chen 2004), little is known about this particular interaction, its prevalence in the field, the natural infection process and variation under different environmental conditions. A considerable drawback is the lack of a common comparable and rapid method to conduct these studies. In particular, there is no reliable technique to quantify endophyte infections, which is crucial to investigate the dynamics of this phenomenon.

Quantitative PCR is a well-established tool for the detection of pathogens in the field of plant-pathogen interactions (Brouwer et al. 2003; Gachon et al. 2004) which has lately also been applied for the detection of the pathogenic oomycete Eurychasma dicksonii in Ectocarpus siliculosus (Gachon et al. 2009). Here, we developed a highly specific qPCR assay that is not only fast and reproducible but also suitable to detect minor amounts of target DNA. This method allows us to examine the prevalence of endophyte infections, i.e. the number of infected thalli in a population, and the severity of infection, i.e. the relative amount of endophyte present in the host tissue. The first aim of this study was to validate this qPCR assay according to recommended guidelines (Bustin et al. 2009). Subsequently, we applied the assay to examine the distribution of filaments of L. elsbetiae along the thallus of S. latissima and the impact of seasonality and geographic variation on endophyte infection rates in different kelp populations. The natural infection process was studied by cultivating laboratory-grown $S$. latissima sporophytes in a seaweed farm and comparing their infection rates with those of wild individuals. Finally, the assay was applied to assess the specificity of L. elsbetiae towards different kelp species.

\section{Material and methods}

\section{In situ algal sampling}

To determine the distribution of endophyte occurrence along the thallus, tissue was punched out $(\varnothing 2.8 \mathrm{~cm})$ at four positions on S. latissima sporophytes: (1) $50 \%$ of the stipe length (piece of $2.8 \mathrm{~cm}$ length), (2) $10 \%$ of the blade length, (3) $50 \%$ of the blade length, and (4) $90 \%$ of the blade length. Samples of $S$. latissima were collected in the same location of different populations, i.e. in Northern Brittany (Perharidy near Roscoff; $\left.48.73^{\circ} \mathrm{N}, 4.00^{\circ} \mathrm{W}, N=10\right)$ in March and April 2016, in Southern Brittany (Locmariaquer; $47.55^{\circ} \mathrm{N}, 2.92^{\circ} \mathrm{W}, N=5$ ) in March 2016, and in Western Scotland (Bridge over the Atlantic; $56.31^{\circ} \mathrm{N}, 5.58^{\circ} \mathrm{W}, N=5$ ) in April 2016. Additionally, two sections were made next to each punchout to look for the presence of endophytic filaments using a light microscope.

For the following studies, all samples were taken from the distal part of the blades (i.e. $90 \%$ of the blade length) of the kelp sporophytes. The onset of endophyte infections in the field was explored by obtaining infection rates of young S. latissima sporophytes with different thallus lengths collected in March 2017 in Northern Brittany (Perharidy; $48.73^{\circ} \mathrm{N}$, $\left.4.00^{\circ} \mathrm{W}, N=10\right)$ that were grouped according to the host length: $3-5 \mathrm{~cm}(N=6), 6-10 \mathrm{~cm}(N=7), 11-15 \mathrm{~cm}(N=8)$, $16-26 \mathrm{~cm}(N=4)$, and $>26 \mathrm{~cm}(N=30)$.

An experimental set-up was used to investigate the impact of natural infection on laboratory-grown sporophytes. Gametophytes descending from spores of S. latissima from Perharidy were seeded on collectors in February 2016 by submerging them in 50-mL Falcon tubes overnight. Then, the collectors were transferred to filtered seawater containing half-strength Provasoli enrichment $(10 \mathrm{~mL}$ solution per L seawater, Provasoli 1968). The young sporophytes were grown in $11^{\circ} \mathrm{C}$ with $40 \mu \mathrm{mol}$ photons $\mathrm{m}^{-2} \mathrm{~s}^{-1}$ with a light/dark cycle of $8 / 16 \mathrm{~h}$ during the first 20 days and 12/12 $\mathrm{h}$ until the end of the experiment. After 68 days, when the sporophytes had reached a length of 2-4 cm, a part of them was transferred to a seaweed farm in vicinity to the wild population ( $4 \mathrm{~km}$ distance) in April 2016 while the rest was maintained in laboratory conditions. In October 2016, infection rates in samples from the individuals cultivated in the farm $(N=57)$ were compared to samples collected from the wild population at Perharidy $(N=30)$ within the same week. The kelps kept in laboratory conditions since April 2016 served as controls $(N=27)$.

Seasonal variation of endophyte infection rates was examined in S. latissima sporophytes collected in March 2016, April 2016, July 2016, September 2016, October 2016, November 2016, December 2016, February 2017 and March 2017 ( $N=30$, each month) in Perharidy.

Saccharina latissima samples were collected in Southern Brittany in March $2016(N=12)$ and in Western Scotland in April $2016(N=30)$ and compared to the samples collected in Perharidy in March and April $2016(N=30$, each) to investigate geographic variation of endophyte infection rates.

To explore host specificity of L. elsbetiae, tissue was punched out from distal parts of blades in L. digitata, L. hyperborea and L. ochroleuca ( $N=10$ for each species) collected in March 2017 in Perharidy and compared to the infection rate of $S$. latissima $(N=30)$. Additionally, $10 \mathrm{~L}$ seawater $(N=3)$ was collected and directly filtered through a $150-\mu \mathrm{m}$ mesh. Subsequently, the water was filtered through 3- $\mu \mathrm{m}$ polycarbonate filters (Nucleopore Track-Etched 
Membranes, Whatman, GE Healthcare, USA) with a vacuum pump. The filters were transferred to cryotubes, frozen in liquid nitrogen and kept in $-20^{\circ} \mathrm{C}$ until DNA was extracted.

All samples were collected haphazardly regardless of possible morphological infection symptoms. The punched-out tissue was soaked dry with tissue paper, transferred to silica gel and stored in silica until DNA extraction.

\section{Monospecific algal cultures}

DNA from monospecific algal cultures was used for settingup and validating the qPCR assay. The cultures of laboratorygrown kelps were started from freshly released spores of mature sporophytes collected at Perharidy. Developing sporophytes were kept in 10-L bottles containing half-strength Provasoli enrichment (10 mL Provasoli solution/L seawater) in $14^{\circ} \mathrm{C}$ and $\sim 20 \mu \mathrm{mol}$ photons $\mathrm{m}^{-2} \mathrm{~s}^{-1}$ at 12 -h light/day with weekly changes of the culture medium. Cultures of the filamentous brown algal endophyte $L$. elsbetiae were grown from the strain LelsPH14-01 obtained from the Bezhin Rosko culture collection (origin Perharidy, France). Isolation of other algal strains from the order Ectocarpales was performed as described by Peters (1991). Ectocarpales cultures were kept in $14{ }^{\circ} \mathrm{C}$ and $5 \mu \mathrm{mol}$ photons $\mathrm{m}^{-2} \mathrm{~s}^{-1}$ at 12 -h light/day with monthly changes of the culture medium (half-strength Provasoli enrichment). The cultured algal material was soaked dry with tissue paper and freeze-dried for DNA extraction.

\section{DNA extraction}

All samples were extracted according to the same protocol to limit differences in extraction yields. The dried algal material was ground in a mechanical bead grinder (Tissuelyser II, Qiagen, Germany) twice for 2 min at $30 \mathrm{~Hz}$. Twenty milligrams of ground material was transferred to a $2-\mathrm{mL}$ Eppendorf tube and used for the following DNA extraction that was adapted after Apt et al. (1995). One millilitre of extraction buffer (100 mM Tris- $\mathrm{HCl}[\mathrm{pH} 7.5], 1.5 \mathrm{M} \mathrm{NaCl}, 2 \%$ CTAB, $50 \mathrm{mM}$ EDTA [pH 8], $50 \mathrm{mM}$ DTT) was added to the ground tissue, and samples were incubated at room temperature on a shaker at $250 \mathrm{rpm}$ for $1 \mathrm{~h}$. One vol of chloroform/ isoamyl alcohol (24:1) was added, and the two phases were mixed by vortexing and centrifuged at $10.000 \mathrm{rpm}$ for $15 \mathrm{~min}$. The upper phase was transferred to a new tube and $0.3 \mathrm{vol}$ ethanol was added drop by drop until polysaccharide precipitation was visible, followed by a second chloroform extraction and another centrifugation step at $10.000 \mathrm{rpm}$ for $15 \mathrm{~min}$. The upper phase was transferred onto the filter of the Nucleospin plant II kit (Macherey-Nagel, Germany), and the protocol recommended by the manufacturer was followed from this step onwards with two elution steps of $50 \mu \mathrm{L}$.

For DNA extraction from the seawater samples, $1.5 \mathrm{~mL}$ of lysis buffer (0.7 M sucrose, $50 \mathrm{mM}$ Tris $\mathrm{pH}$ 8, $40 \mathrm{mM}$ EDTA) was added to each filter. One hundred microliter lysozyme $\left(20 \mathrm{mg} \mathrm{mL}^{-1}\right.$ ) was added, and samples were shaken at $37^{\circ} \mathrm{C}$ for $45 \mathrm{~min}$. Twenty microliter proteinase $\mathrm{K}\left(20 \mathrm{mg} \mathrm{mL}^{-1}\right)$ and $100 \mu \mathrm{L} 20 \%$ SDS was added, and samples were homogenised by inversion and incubated at $55^{\circ} \mathrm{C}$ for $1 \mathrm{~h}$. The content was transferred to a new tube and 1 vol phenol-chloroformisoamyl alcohol $(25: 24: 1)$ was added; the phases were mixed and then centrifuged for $15 \mathrm{~min}$ at $4500 \mathrm{rpm}$ at $4{ }^{\circ} \mathrm{C}$. The supernatant was mixed with 1 vol of the binding buffer from the Nucleospin plant II kit (Macherey-Nagel, Germany), and the protocol recommended by the manufacturer was followed from this step onwards with two elution steps of $50 \mu \mathrm{L}$.

DNA concentrations were measured with a Qubit Fluorometer (Thermo Fisher, USA) and diluted to $0.05 \mathrm{ng}$ DNA $\mu \mathrm{L}^{-1}$ with autoclaved milliQ-filtered $\mathrm{H}_{2} \mathrm{O}$.

\section{qPCR and evaluation of the assay}

The first primer pair CG64 and CG65 (Gachon et al. 2009) matched the $18 \mathrm{~S}$ rDNA of all Ectocarpales and Laminariales (72-bp amplicon size) and was used to amplify $18 \mathrm{~S}$ rDNA from both, host and endophyte DNA. The second primer pair LelsITS1-F2 (TTTCGAGAGCTTTCGAGAGG) and LelsITS1-R2 (TCTTCACGCCTCTTACATGG) (83-bp amplicon size) was designed to specifically match the partial ITS1 of Laminarionema elsbetiae. Specificity of the latter primer pair was tested by blasting the sequence and testing it with the DNA from 10 other brown algae diluted to $0.05 \mathrm{ng}$ DNA $\mu \mathrm{L}^{-1}$, including algal endophytes from the order Ectocarpales and possible hosts from the order Laminariales (Fig. S1). The qPCR products were run in a $2.5 \%$ agarose gel electrophoresis at $100 \mathrm{~V}$ for $25 \mathrm{~min}$ to check for presence or absence of bands.

Artificial mixtures of host and endophyte DNA were assembled to assess if different amounts of endophyte DNA were detectable reliably. Therefore, $1 \mathrm{ng}$ of DNA from S. latissima was mixed with $0.0024,0.012,0.06$ and $0.3 \mathrm{ng}$ of DNA from L. elsbetiae.

Standard curves for the CG primer pair were constructed in triplicates with 1:5 serial dilutions of $S$. latissima DNA, extracted from a laboratory-grown sporophyte, ranging from a concentration of $0.5 \mathrm{ng}$ to $6.4 \times 10^{-6} \mathrm{ng}$. Standard curves for the LelsITS1 primer pair were constructed with 1:2 serial dilutions of L. elsbetiae DNA, extracted from the strain LelsPH14-01, ranging from a concentration of $0.375 \mathrm{ng}$ to $1.14 \times 10^{-5} \mathrm{ng}$.

A total of $2.5 \mu \mathrm{L}$ LightCycler 480 SYBR Green I Master (2x, Roche Diagnostics, Germany) was mixed with the primers $(400 \mathrm{nM})$, and $2.9 \mu \mathrm{L}$ of this mix was added to $2.1 \mu \mathrm{L}$ of diluted DNA $\left(0.05 \mathrm{ng} \mu \mathrm{L}^{-1}\right)$. Real-time PCR was performed on a LightCycler 480 (Roche Life Science, Germany) in white 384-well plates, sealed with adhesive foil. 
A 5-min denaturation step at $95^{\circ} \mathrm{C}$ was followed by 55 cycles of $10 \mathrm{~s}$ at $95^{\circ} \mathrm{C}$ and $15 \mathrm{~s}$ at $60^{\circ} \mathrm{C}$ and $15 \mathrm{~s}$ at $72{ }^{\circ} \mathrm{C}$. After each run, a dissociation curve was obtained by heating the samples from 65 to $97^{\circ} \mathrm{C}$. The dissociation curves indicated a single product for both primer pairs (data not shown). All samples were run in triplicates, as recommended by Pfaffl (2004), and autoclaved milliQ $\mathrm{H}_{2} \mathrm{O}$ was used as negative control. For relative quantification, the differences between the quantification cycles $\left(\Delta \mathrm{C}_{\mathrm{q}}\right)$ obtained by two qPCRs with the different primer pairs run in parallel on the same DNA sample were measured, as by Gachon et al. (2009). The resulting $\Delta \mathrm{C}_{\mathrm{q}}$ values correlate negatively to the relative amount of endophyte DNA in the sample.

No relative quantification was performed for the water samples. Only the L. elsbetiae-specific primer pair was used in a $\mathrm{qPCR}$ reaction, and the final $\mathrm{qPCR}$ product was run in a $2.5 \%$ agarose gel electrophoresis to check for presence or absence of endophyte DNA.

\section{Data analysis}

Cycle thresholds were calculated with the LightCycler 480 Software (Roche, Germany) and exported to Excel 2013 (Microsoft, USA) where $\Delta \mathrm{C}_{\mathrm{q}}$ values of each DNA sample were determined. Values are reported as average \pm standard deviation. Graphs of the standard curves were drawn with GraphPad Prism (GraphPad Prism Software, Inc., USA), and the heat map was constructed in R Studio (RStudio, Inc., USA). SPSS (IBM Corp. Released 2013. IBM SPSS Statistics for Windows, Version 22.0. Armonk, NY: IBM Corp.) was used to perform statistical analyses. Normality of the data was tested with the Shapiro-Wilk test and homogeneity of variances with the Levene test. Data with normal distribution and homogeneous variances was analysed with oneway ANOVA. In the case of heterogeneous variances, the non-parametric Kruskal-Wallis test was used.

\section{Results}

\section{Set-up and validation of the qPCR assay}

The specificity of the endophyte-specific primer pair was verified by blasting the sequence (BLASTN search), and no other species showed $100 \%$ identity over the full query. Furthermore, the primers were tested with 10 other brown algal species. Electrophoresis on an agarose gel resulted in no visible bands for any sample except $L$. elsbetiae, suggesting a strong specificity of the primer pair (Online Resource 1).

Artificial mixtures with the same amount of host DNA and different amounts of endophyte DNA were used to test if varying amounts of $L$. elsbetiae could be detected reliably, even in low concentrations (Online Resource 2A+B).
Similar quantification cycles $\left(\mathrm{C}_{\mathrm{q}}\right)$ were obtained with the CG primer pair. Since only small amounts of endophyte DNA were added, the total amount of DNA did not change significantly (Online Resource 2A). At the contrary, quantification of the same mixtures with the endophyte-specific primer pair (Online Resource $2 \mathrm{~B}$ ) resulted in different $\mathrm{C}_{\mathrm{q}}$ values, showing that the qPCR amplification was sufficiently discriminant to detect different concentrations of total endophyte DNA over the assessed range from 0.0024 to $0.3 \mathrm{ng} \mu \mathrm{L}^{-1}$ total DNA.

Standard curves were drawn for both primer pairs to define the linear dynamic range of stable quantification and to compare the efficiency of amplification. As the efficiency of both primer pairs was similar $88.74 \%$ for the CG primer pair and $91.08 \%$ for the Laminarionema specific primer pair, Online Resource $3 \mathrm{~A}+\mathrm{B}$ ), no efficiency correction was applied. For the primer pair CG64 and CG65, a reliable quantification was possible for cycle numbers between 18 and 29 (Online Resource $3 \mathrm{~A}$ ). $\mathrm{C}_{\mathrm{q}}$ values of all samples lay within the range of this standard curve. For the LelsITS1 primer pair, the linear quantification range was between 19 and 32 cycles (Online Resource 3B). Thus, a maximal $\Delta \mathrm{C}_{\mathrm{q}}$ value of 14 (32-18) was set for stable quantification of $L$. elsbetiae according to the standard curves. Samples with higher $\mathrm{C}_{\mathrm{q}}$ values or no endophytes were marked as "undetected".

\section{Distribution of endophyte filaments along the thallus of S. latissima}

To determine the distribution of L. elsbetiae along the thallus of S. latissima, a relative infection map was established by quantifying relative infection rates at four different positions along the thallus. Endophyte filaments of L. elsbetiae were unequally distributed within the host, with significantly more endophyte DNA being present in the blade tip $\left(\Delta \mathrm{C}_{\mathrm{q}}=10.8 \pm 3.17\right)$ than in the stipe $\left(\Delta \mathrm{C}_{\mathrm{q}}=\right.$ $13.72 \pm 0.72)$, at $10 \%$ of the blade length $\left(\Delta \mathrm{C}_{\mathrm{q}}=13.94 \pm\right.$ $0.29)$ and at $50 \%$ of the blade length $\left(\Delta \mathrm{C}_{\mathrm{q}}=13.62 \pm 0.63\right.$, Fig. 1, Kruskal-Wallis test, $p \leq 0.01$, Online Resource 5). The unequal distribution along the thallus was the same in kelps from all three geographic locations. Due to this result, the samples for the following studies were taken in the blade tips of the kelps, where most endophytes were expected to be present.

The presence of filamentous brown algae at the four positions in the same Saccharina sporophytes was also examined in microscopic sections (Fig. 2). Eighty percent of the thalli from Northern Brittany and Western Scotland and $60 \%$ of the thalli from Southern Brittany contained filamentous algae in the blade tips (Fig. 2b). Seventy percent and $20 \%$ of the stipe sections of sporophytes from Northern Brittany and Southern Brittany, respectively, contained endophytic filaments (Fig. 2a) while no filament was detected in the stipe sections 


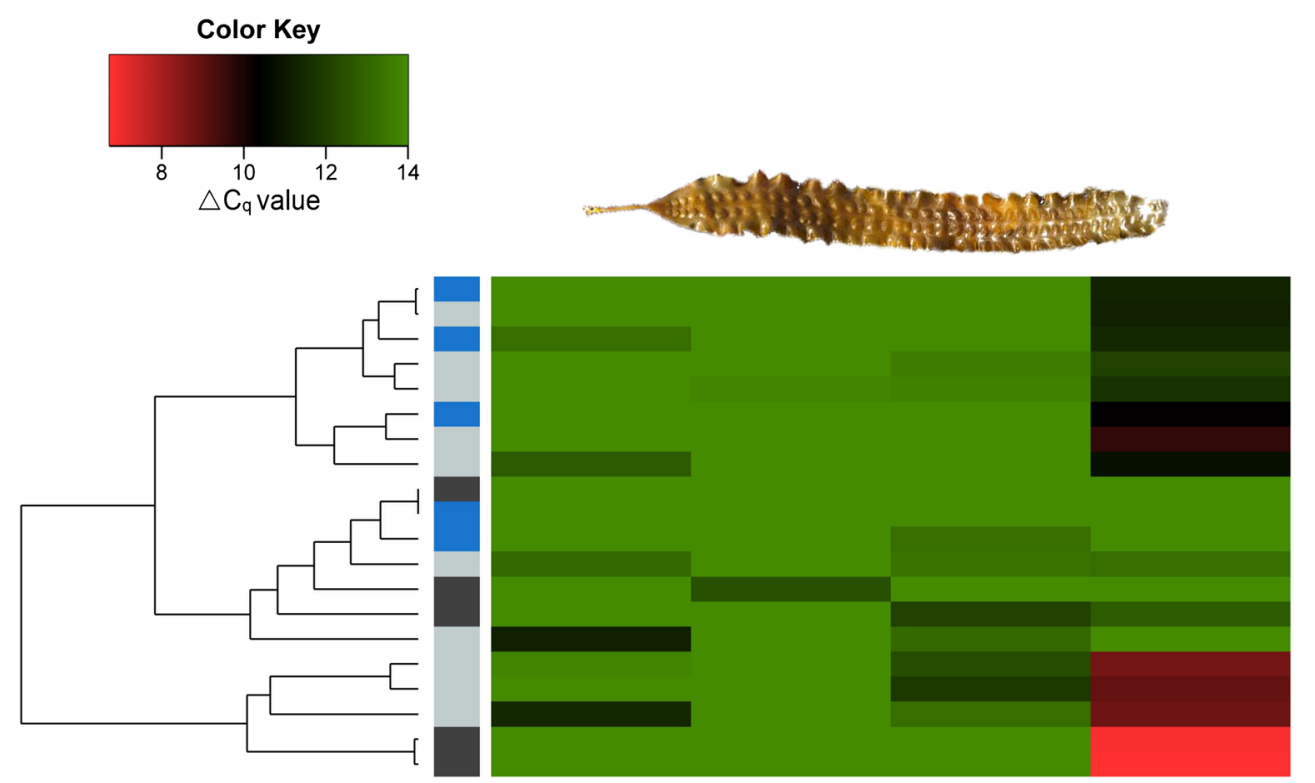

Fig. 1 Distribution of endophyte DNA in field sporophytes of S. latissima (>160 cm length) collected between March and April 2016. The small column on the left indicates the geographic origin of the sporophytes: light grey $=$ Perharidy (Northern Brittany) $N=10$, light blue = Locmariaquer (Southern Brittany) $N=5$, and dark grey = bridge over the Atlantic (Western Scotland) $N=5$. The four columns of the heat

of the S. latissima sporophytes from Western Scotland. In all examined sections, no endophytic filaments were visible in the intermediate sections (positions 2 and 3 in Fig. 1).

\section{Infection rates in young kelps}

The occurrence of the endophyte infection in the field was investigated by determining relative infection rates of young S. latissima sporophytes. One hundred percent of map indicate the four positions: (1) $50 \%$ of the stipe; (2) $10 \%$ of the blade length = youngest part of the blade, near meristem; (3) $50 \%$ of the blade length; and (4) $90 \%$ of the blade length = oldest part of the blade. The colours of the heat map represent $\Delta \mathrm{C}_{\mathrm{q}}$ values obtained by qPCR: green represents absence and red strong presence of $L$. elsbetiae

the young $S$. latissima sporophytes collected in Northern Brittany contained DNA of L. elsbetiae, compared to $93 \%$ of infected thalli in old (>30 cm) sporophytes collected at the same time (Fig. 3a). When comparing the relative infection rates, no significant difference appeared in the $\Delta \mathrm{C}_{\mathrm{q}}$ between sporophytes of all lengths $\left(\Delta \mathrm{C}_{\mathrm{q}}=9.82 \pm\right.$ 0.6 , Fig. 3b) except for the samples with a thallus length from 6 to $10 \mathrm{~cm}$ where infection rates were slightly lower $\left(\Delta \mathrm{C}_{\mathrm{q}}=11.43 \pm 0.7\right.$, Fig. $\left.3 \mathrm{~b}\right)$.
Fig. 2 a A microscopic section of the stipe (position $1,50 \%$ of the stipe length) of $S$. latissima from Northern Brittany. b A

microscopic section of the blade tip (positions 4, $90 \%$ of the blade length) of S. latissima from Northern Brittany. Red arrows indicate endophytic filaments, and the scale bar presents $25 \mu \mathrm{m}$
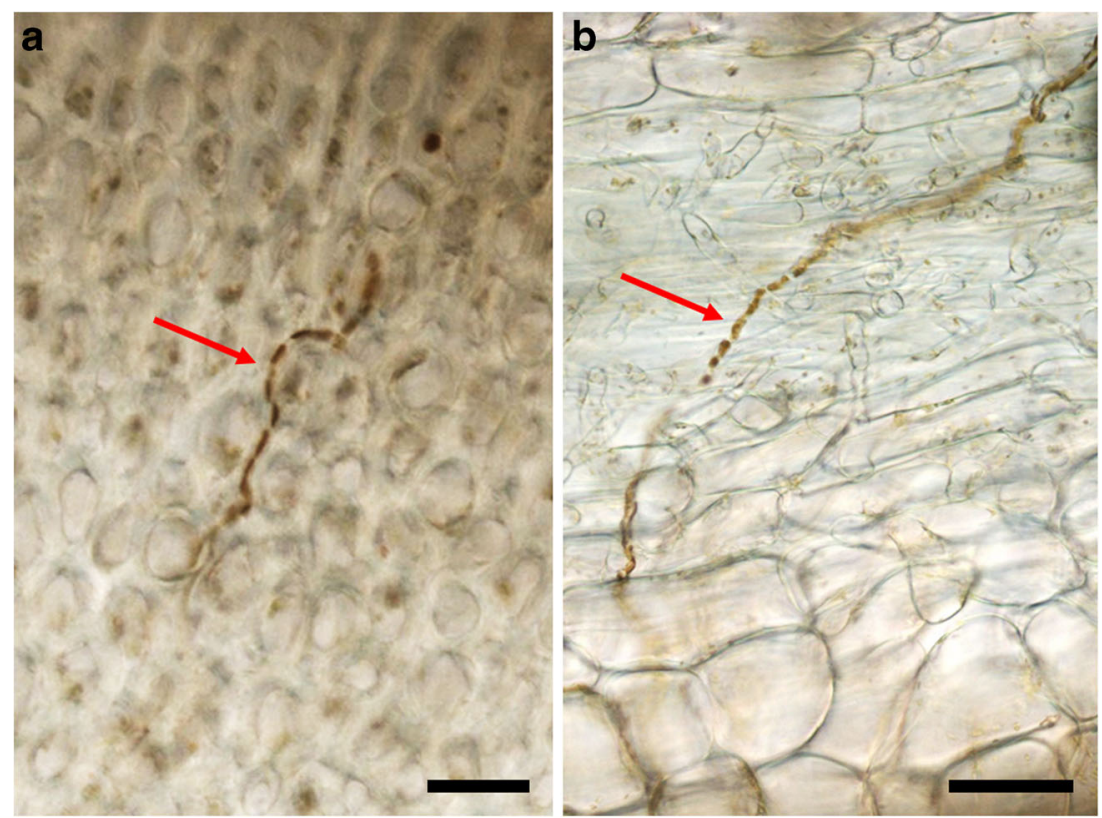
Fig. 3 a Percentage of S. latissima sporophytes with different thallus lengths infected with L. elsbetiae. $\mathbf{b} \Delta \mathrm{C}_{\mathrm{q}}$ values obtained by qPCR represent the relative amount of $L$. elsbetiae in S. latissima individuals of different thallus lengths obtained from punch-outs of blade tips collected in March 2017 (3-5 cm, $N=6 ; 6-10 \mathrm{~cm}, N=7 ; 11-15 \mathrm{~cm}$, $N=8 ; 16-26 \mathrm{~cm}, N=4 ;>30 \mathrm{~cm}$, $N=30$ ). Whiskers indicate the smallest and largest values, and letters indicate statistically significant differences (one-way ANOVA)

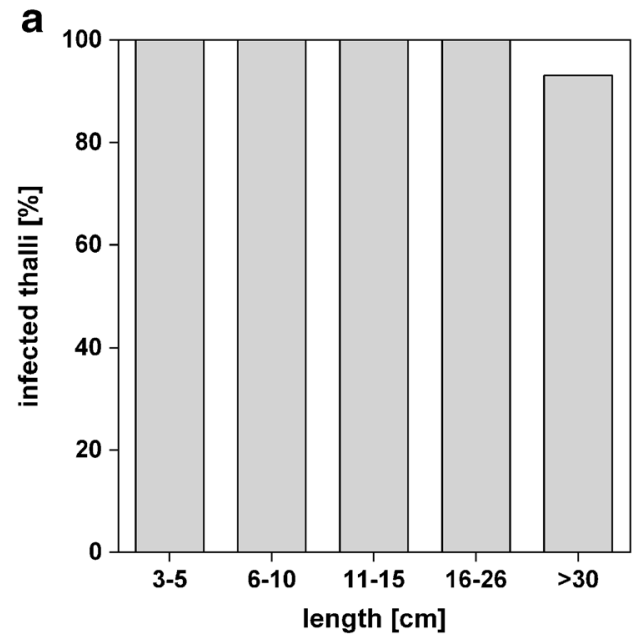

\section{Natural infection of laboratory-grown samples in a seaweed farm}

The course of natural infection of S. latissima with $L$. elsbetiae was further explored by an experimental set-up where laboratory-grown samples were transferred to a seaweed farm for 6 months and infection rates were compared to samples from a wild population. The number of thalli infected with $L$. elsbetiae was more than four times higher in wild samples ( $87 \%$ of infected thalli) than in the samples grown in the seaweed farm in close vicinity to the wild population (19\%, Fig. 4a). No endophytes were detected in the laboratory controls (Fig. 4a). While the laboratory-grown samples in the seaweed farm were heavily covered with epiphytes (data not shown), the qPCR revealed significantly lower infection rates by the endophyte $L$. elsbetiae $\left(\Delta \mathrm{C}_{\mathrm{q}}=11.81 \pm 1.4\right)$ as compared to wild samples $\left(\Delta \mathrm{C}_{\mathrm{q}}=8.99\right.$ \pm 2.5 ) (one-way ANOVA, $p \leq 0.01$, Fig. $4 \mathrm{~b}$, Online Resource 6). b

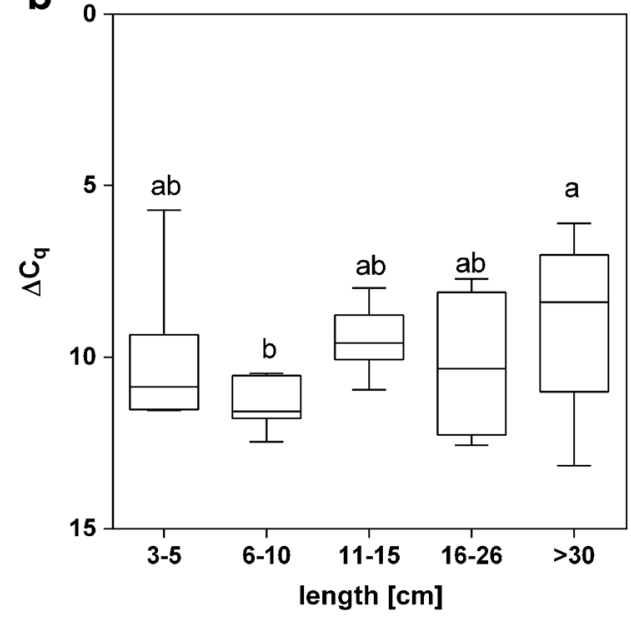

\section{Seasonal variation of relative infection rates}

To examine the seasonal variation of infection in a natural population, regular samplings took place in Northern Brittany from March 2016 to March 2017. The endophyte prevalence in the $S$. latissima population ranged between 73 and $93 \%$ with the lowest number of infected kelps detected in February 2017 (73\%) and most kelps infected in July 2016 and March 2017 (93\%, Fig. 5a). The relative amount of L. elsbetiae filaments in infected thalli also increased during spring and was significantly higher between July and September $\left(\Delta C_{q}=7.38 \pm 1.8\right.$ and $7.06 \pm 2.4$, respectively) than during the rest of the year (one-way ANOVA, $p \leq 0.01$, Fig. 5b, Online Resource 6). Infection rates decreased in October, reaching the lowest value in February $\left(\Delta \mathrm{C}_{\mathrm{q}}=10.75 \pm 2.1\right)$ and increasing again in March (Fig. 5b).
Fig. 4 a Percentage of S. latissima sporophytes from different origins infected with L. elsbetiae. $\mathbf{b} \Delta \mathrm{C}_{\mathrm{q}}$ values obtained by qPCR represent the relative amount of $L$. elsbetiae in $S$. latissima obtained in October 2016 from a wild population in Northern Brittany $(N=30)$ and from laboratory-grown samples transferred to a seaweed farm $(N=57)$ and kept under laboratory conditions $(N=27)$. Whiskers indicate the smallest and largest values, and letters indicate statistically significant differences (one-way ANOVA), n.d. = no L. elsbetiae detected by qPCR
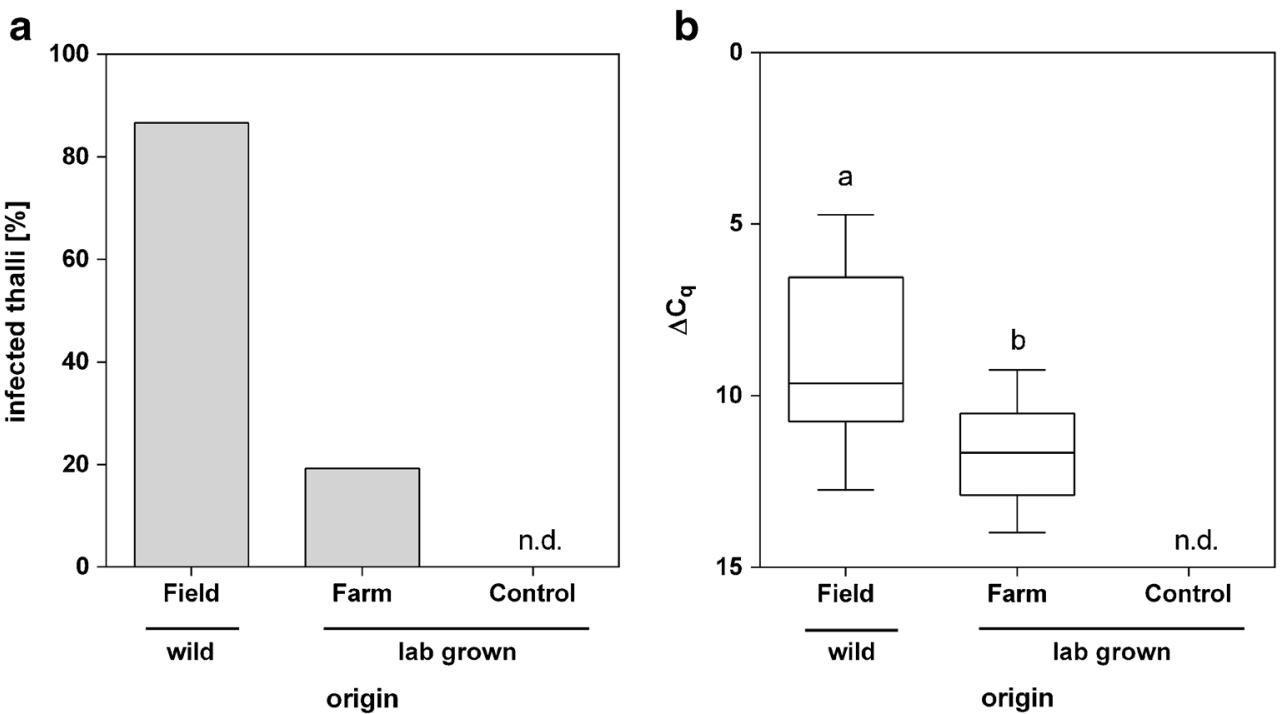
Fig. 5 a Percentage of $S$. latissima sporophytes collected in different months infected with L. elsbetiae in a population of S. latissima at Perharidy (Northern Brittany). b Seasonal changes in the relative amount of L. elsbetiae in a population of S. latissima at Perharidy (Northern Brittany) represented by $\Delta \mathrm{C}_{\mathrm{q}}$ values obtained from punch-outs of blade tips of 30 individuals per sampling. Whiskers indicate the smallest and largest values, and letters indicate statistically significant differences (one-way ANOVA)

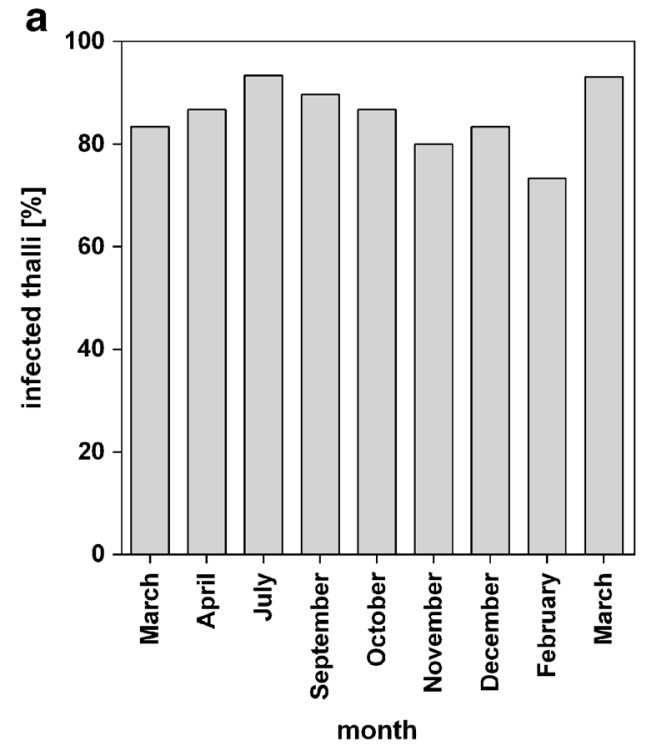

\section{Geographic variation of relative infection rates}

Geographic variation of relative infection rates of L. elsbetiae in S. latissima sporophytes was determined by samplings in three different populations in Southern Brittany, Northern Brittany and Western Scotland during March and April 2016. While 85 and $93 \%$ of the sporophytes collected in Northern Brittany and Western Scotland, respectively, were infected with the endophyte, only $33 \%$ of sporophytes from Southern Brittany contained detectable amounts of endophytic filaments in their blade tips (Fig. 6a). Moreover, the relative infection rate by L. elsbetiae was shown to differ significantly between Western Scotland and Brittany (one-way ANOVA, $p=0.01$, Fig. 6b, Online Resource 6). Kelps collected in Southern Brittany (Locmariaquer) contained significantly less L. elsbetiae $\left(\Delta \mathrm{C}_{\mathrm{q}}=11.78 \pm 2.4\right)$ than the ones from Northern Brittany (Perharidy, $\Delta \mathrm{C}_{\mathrm{q}}=9.93 \pm 2.3$ ). The sporophyte samples collected at the Bridge over the Atlantic (Western Scotland) were most heavily infected $\left(\Delta \mathrm{C}_{\mathrm{q}}=8.39 \pm 3\right.$, Fig. $\left.6 \mathrm{~b}\right)$.

\section{Host specificity}

To explore the host specificity of $L$. elsbetiae, endophyte prevalence and infection rates of $S$. latissima were compared to infection rates of the adjacent kelp species L. hyperborea, L. digitata and L. ochroleuca. While $93 \%$ of the S. latissima sporophytes were infected with $L$. elsbetiae, endophyte DNA was only detected in 20 and $50 \%$ of the L. digitata and L. ochroleuca individuals, respectively, collected at the same location and the same time (Fig. 7a). Laminarionema elsbetiae was not detected in DNA from any sample of L. hyperborea. Additionally, infection rates in $S$. latissima sporophytes were significantly higher $\left(\Delta \mathrm{C}_{\mathrm{q}}=8.97 \pm 2\right)$ than in L. digitata and L. ochroleuca individuals adjacent to the Saccharina
Fig. 6 a Percentage of S. latissima sporophytes from different geographic origins infected with L. elsbetiae. b $\Delta \mathrm{C}_{\mathrm{q}}$ values obtained by qPCR represent the relative amount of L. elsbetiae in S. latissima, obtained from punch-outs of blade tips of individuals from Western Scotland $(N=30)$, Northern Brittany $(N=60)$ and Southern Brittany $(N=12)$, collected in March and/or April 2016. Whiskers indicate the smallest and largest values, and letters indicate statistically significant differences (one-way ANOVA)
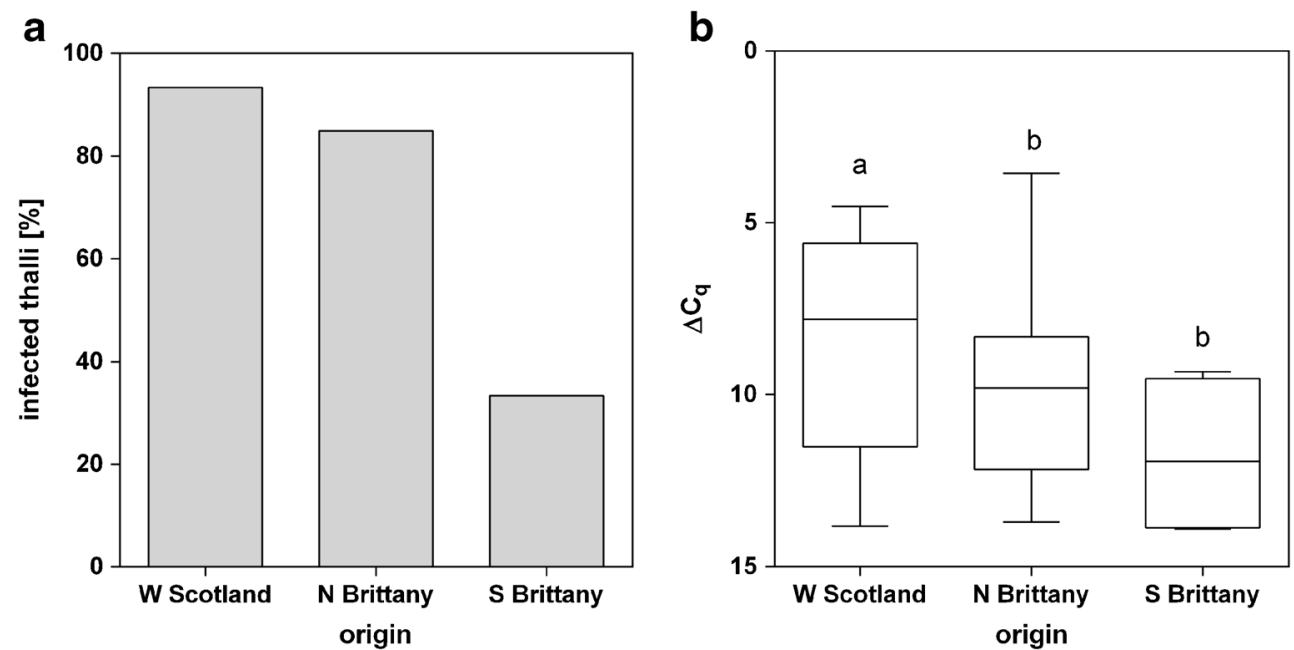
Fig. 7 a Percentage of sporophytes from different species infected with L. elsbetiae. b $\Delta \mathrm{C}_{\mathrm{q}}$ values obtained by $\mathrm{qPCR}$ represent the relative amount of L. elsbetiae in S. latissima (Slat, $N=30$ ), L. hyperborea (Lhyp, $N=10)$, L. digitata $($ Ldig, $N=10)$ and L. ochroleuca (Loch, $N=10$ ), obtained from punch-outs of blade tips, collected in March 2017. Whiskers indicate the smallest and largest values, and letters indicate statistically significant differences (one-way ANOVA), n.d, no L. elsbetiae detected by qPCR

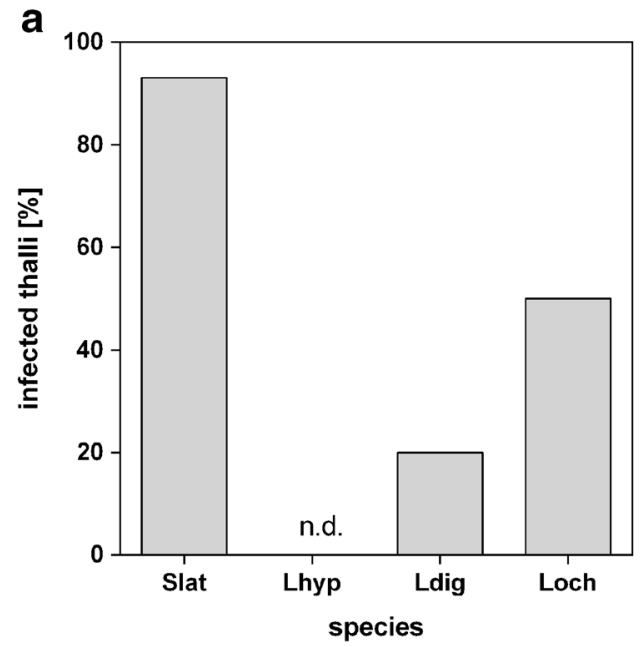

population $\left(\Delta \mathrm{C}_{\mathrm{q}}=11.98 \pm 0.9\right.$ and $12.58 \pm 1.3$, respectively, one-way ANOVA, $p \leq 0.01$, Fig. 7b, Online Resource 6).

DNA of $L$. elsbetiae was also specifically amplified in the seawater samples collected at three locations in close vicinity to Saccharina sporophytes (Online Resource 4).

\section{Discussion}

\section{A specific and reliable qPCR approach for epidemiological studies}

In our study, we detected a high prevalence of $L$. elsbetiae in S. latissima with up to $100 \%$ of infected individuals in Northern Brittany. This is in consistence with previous epidemiological studies about filamentous endophytes in brown algae in the Atlantic and Pacific Ocean (Andrews 1977; Lein et al. 1991; Peters and Schaffelke 1996; Ellertsdóttir and Peters 1997; Peters 2003). Until now, epidemiological studies were based on different methodological approaches, rendering them difficult to compare. Andrews (1977) determined an infection rate of $20 \%$ by quantifying galls on S. latissima presumably caused by a filamentous brown algal endophyte. However, the presence of endophyte filaments is not always directly connected to the occurrence of disease symptoms (Ellertsdóttir and Peters 1997; Gauna et al. 2009b) and indeed most of the sporophytes infected with L. elsbetiae sampled in our study did not show any disease symptoms. Thus, an epidemiological survey based on the occurrence of symptoms could lead to an underestimation if endophytes do not cause identifiable changes in the host. Other studies were based on counting endophyte filaments in microscopic sections (Lein et al. 1991; Gauna et al. 2009a). While this method provides valuable information about the presence of filamentous endophytes, a precise quantification by visual scoring and the subsequent statistical b

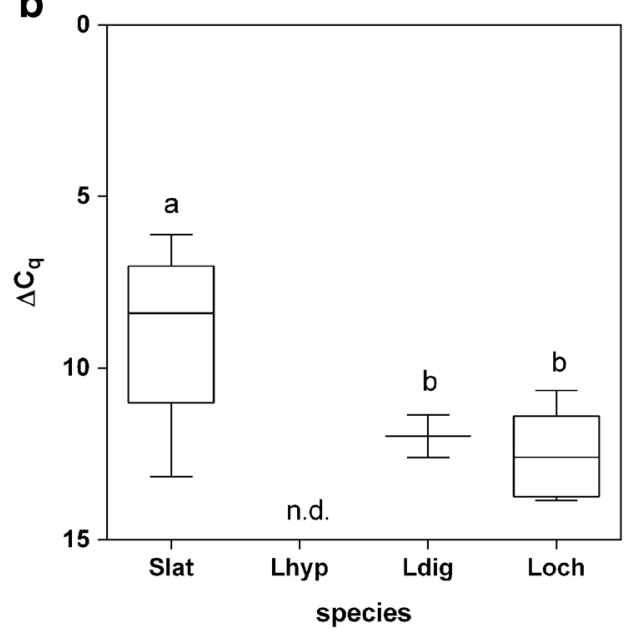

analysis are difficult. Furthermore, filamentous endophytes are difficult to identify in microscopic sections as species are morphologically little differentiated (Eggert et al. 2010). For a trustworthy identification, the endophyte needs to be isolated and cultivated in a time-consuming process (Ellertsdóttir and Peters 1997; Peters 2003; Amsler et al. 2009).

The evaluation of our qPCR assay confirmed that this new approach is suitable not only for a relative quantification of the prevalence and the severity of infection but also for a specific, rapid and sensitive identification of $L$. elsbetiae. A possible concern might be that the L. elsbetiae-specific primer pair could amplify other so far unknown species. However, up to now, only one species of the genus Laminarionema is described and the related genera Laminariocolax and Microspongium which also contain filamentous endophytes (Peters and Burkhardt 1998; Peters 2003) are not targeted by the L. elsbetiae-specific primer pair (Online Resource 1). The results obtained using the qPCR assay correlate with the detection of endophytic filaments by microscopy in highly infected parts. Moreover, low amounts of endophyte DNA could be detected by qPCR in parts of the blade where no filaments where visible in the microscopic sections showing that the qPCR assay is a more sensible tool than microscopy.

\section{Early occurrence of the infection in nature}

Since it has been reported for other host-endophyte pairs that endophytic filaments can be distributed unequally within the host (Amsler et al. 2009; Gauna et al. 2009a), we investigated the distribution of endophytes along the host thallus and confirmed that most endophytes were located in the blade tips of S. latissima. This stresses the importance of careful planning of samplings for epidemiological studies, as the infection rates may differ significantly depending on where exactly on the thallus samples are taken. The meristematic tissue of kelps lies at the junction between stipe and blade; the blade tip is 
therefore the oldest part of the sporophyte (Wilkinson 1995). The concentration of endophyte filaments in the blade tip could indicate that hosts are infected very early in their life, and the endophyte subsequently stays in the same tissue while this part grows further away from the meristem. To test this hypothesis, we collected young kelps of different lengths in order to compare the infection rates with the old sporophytes. Laminarionema elsbetiae was detected in all of the sampled kelps, even the very young ones $(>5 \mathrm{~cm})$, suggesting an early infection of the kelp. Furthermore, kelps from a seaweed farm, which had been grown in lab conditions for 10 weeks, were significantly less infected than wild kelps although the farm and population were in vicinity to each other (4 km distance), i.e. exposed to similar environmental conditions. These kelps were kept in the laboratory during their early life, and once they were taken out to the sea, the cell walls might have already changed enough to make it more difficult for the endophyte to enter (Apt 1988a). Similarly, in the case of the closely related pacific kelp species Saccharina japonica, only young specimen could be infected by the filamentous brown algal endophyte Streblonema sp., while the filaments of the endophyte could not penetrate the tissue of mature kelps, unless it presented a wounding site (Apt 1988a). Previous experimental infection of S. latissima with Laminarionema used very young host sporophytes $(<10 \mathrm{~mm}$ in length), which were readily infected (Heesch and Peters 1999). Overall, our results suggest that $S$. latissima is infected with $L$. elsbetiae while it is still very young and keeping Saccharina cultures under controlled conditions for a certain amount of time could reduce infection rates of cultivated S. latissima with L. elsbetiae.

\section{Variation of infection rates}

The severity of infection differed not only along the thallus but also depended on seasonal and geographic location. Infection rates within the Saccharina population in Northern Brittany were significantly higher in summer as compared to the rest of the year. This is in agreement with observations on endophytic infections in S. latissima and two other kelp species on Helgoland (Ellertsdóttir and Peters 1997) and in S. latissima in the Pacific Northwest (Andrews 1977). However, as seasonal samplings were only conducted in Northern Brittany, additional samplings at other locations are necessary to confirm a general pattern of seasonal variation. Kelps may lose distal parts of their blade in winter, thereby shedding infected tissue (Ellertsdóttir and Peters 1997). Furthermore, it is possible that growth rates of the endophyte benefit from higher summer temperatures. Seasonal variation of infection rates could also be connected to the life cycle of $L$. elsbetiae. The endophyte spreads between hosts via zoospores that penetrate the host tissue (Heesch and Peters 1999) and on Helgoland fertile structures in L. elsbetiae were found only during spring (Peters and Ellertsdóttir 1996). As we were able to detect
L. elsbetiae DNA in seawater samples taken around a S. latissima population in spring, it is likely that spores of the endophyte were present in the seawater during this time, spreading to infect new hosts.

Significant differences were found between kelp populations from France and Scotland both, in endophyte prevalence and infection rates, increasing from Southern Brittany to Western Scotland. Seawater temperature is decreasing along a latitudinal gradient from $14.1{ }^{\circ} \mathrm{C}$ in Locmariaquer (Southern Brittany) to $12.4^{\circ} \mathrm{C}$ in Perharidy (Northern Brittany) and $9.5^{\circ} \mathrm{C}$ of average annual sea surface temperature in Oban (Western Scotland, data provided by the National Oceanic and Atmospheric Administration). However, temperature is not the only factor that discriminates the three populations. The Saccharina populations in Western Scotland and Northern Brittany are also denser than the one in Southern Brittany, which lies near the distribution limit of S. latissima and host density plays an important role in spreading infective agents like spores (Clay 1990). Furthermore, the different examined populations are exposed to different strengths of currents. Ellertsdóttir and Peters (1997) found that endophyte prevalence was higher at more wave-exposed sites. Water depth is another factor that has a significant impact on endophyte distribution, with stronger disease symptoms in shallow water than in deep water (Schaffelke et al. 1996; Ellertsdóttir and Peters 1997) either by reducing the host fitness under higher UV radiation or by favouring endophyte growth rates due to higher PAR (Schaffelke et al. 1996). Since environmental factors seem to have a significant impact on the host-endophyte relationship, experiments under controlled laboratory conditions are necessary to examine the effect of single environmental factors on the interaction between S. latissima and L. elsbetiae.

\section{Host specificity of $L$. elsbetiae}

Both the number of infected thalli and the severity of infection with L. elsbetiae were significantly higher in S. latissima than in other kelps collected in the vicinity. Similar to results obtained by microscopic observations and subsequent isolation from kelps on Helgoland (Ellertsdóttir and Peters 1997), we detected L. elsbetiae also in $20 \%$ of $L$. digitata. Additionally, DNA of L. elsbetiae was found in $50 \%$ of L. ochroleuca sporophytes, but not in L. hyperborea, whereas $L$. elsbetiae spores were likely to be present in the surrounding seawater.

Laminarionema elsbetiae was first described based on isolates from S. japonica in Japan, where it was not found infecting any other kelp species in close vicinity, pointing out a high specificity of the infection (Kawai and Tokuyama 1995). Electron microscopy of the infection process suggested that L. elsbetiae enters the tissue of $S$. latissima by enzymatic dissolution of the cell wall (Heesch and Peters 1999), but so far, it is still unclear what exactly defines the ability of the endophyte to infect certain hosts. Chemical differences in kelp 
cell wall compositions - for example in the content of celluloses, hemicelluloses and alginates (Siegel and Siegel 1973) - could play an important part in the host specificity of algal endophytes. As the cell wall composition of brown algae is known to vary based on environmental conditions (Rosell and Srivastava 1984; Adams et al. 2011; DeniaudBouët et al. 2014), these differences could also contribute to geographic and seasonal variations in the endophyte prevalence. Furthermore, host specificity might be based on different kelp species having specific defence reactions. The oxidative burst upon elicitation with oligoguluronates, an early defence response, differs amongst several members of the Laminariales (Küpper et al. 2002). Finally, the ability of an endophyte to infect a host is also strongly linked to the life cycles of both, the host and the endophyte. As our results suggest that kelps are infected at a very young age, host specificity might be coupled to the occurrence of young sporophytes of different species in the field and the synchronisation of spore release from L. elsbetiae. Fertility periods and subsequently the appearance of young sporophytes are known to be variable within the Laminariales (Bartsch et al. 2008), but further studies on the life cycle of $L$. elsbetiae are necessary to better understand these relationships.

Overall, the consistency in results of our approach with microscopic observation and previous epidemiological studies based on other methods confirm the reliability of our qPCR assay. This efficient tool is well adapted for routine application and processing of large sample numbers for epidemiological studies on infections of $S$. latissima with $L$. elsbetiae. Moreover, the approach could be easily transferred to other host-endophyte pairs by designing specific primers and therefore be applied to extensive studies on kelp-endophyte interactions.

Acknowledgements We would like to thank Laëtitia Mest for providing us DNA to test primer specificity and Svenja Heesch for assistance with the sampling. We appreciate the help from our colleagues from the Marine Service of Roscoff during the material collection and the implementation of the experiments. We also thank the anonymous reviewer for extensive proofreading of our manuscript.

Funding information The presentation of this work at the ISAP2017 was supported by a fellowship provided by the Global Seaweed Network (UK NERC IOF Pump-priming + scheme NE/L013223/1). This project has received funding from the European Union's Horizon 2020 research and innovation programme under the Marie Skladowska-Curie grant agreement $\mathrm{N}^{\circ} 642575$ and by the project IDEALG (France: ANR-10-BTBR-04).

Open Access This article is distributed under the terms of the Creative Commons Attribution 4.0 International License (http:// creativecommons.org/licenses/by/4.0/), which permits unrestricted use, distribution, and reproduction in any medium, provided you give appropriate credit to the original author(s) and the source, provide a link to the Creative Commons license, and indicate if changes were made.

\section{References}

Adams JM, Gallagher JA, Donnison IS (2009) Fermentation study on Saccharina latissima for bioethanol production considering variable pre-treatments. J Appl Phycol 21:569-574

Adams JMM, Ross AB, Anastasakis K, Hodgson EM, Gallagher JA, Jones JM, Donnison LS (2011) Seasonal variation in the chemical composition of the bioenergy feedstock Laminaria digitata for thermochemical conversion. Bioresour Technol 102:226-234

Amsler CD, Amsler MO, McClintock JB, Baker BJ (2009) Filamentous algal endophytes in macrophytic Antarctic algae: prevalence in hosts and palatability to mesoherbivores. Phycologia 48:324-334

Andrews JH (1977) Observations on the pathology of seaweeds in the Pacific Northwest. Can J Bot 55:1019-1027

Apt KE (1988a) Etiology and development of hyperplasia induced by Streblonema sp. (Phaeophyta) on members of the Laminariales (Phaeophyta). J Phycol 24:28-34

Apt KE (1988b) Galls and tumor-like growths on marine macroalgae. Dis Aquat Org 4:211-217

Apt KE, Clendennen SK, Powers DA, Grossman AR (1995) The gene family encoding the fucoxanthin chlorophyll proteins from the brown alga Macrocystis pyrifera. Mol Gen Genet 246:455-464

Bartsch I, Wiencke C, Bischof K, Buchholz CM, Buck BH, Eggert A, Feuerpfeil P, Hanelt D, Jacobsen S, Karez R, Karsten U, Molis M, Roleda MY, Schubert H, Schumann R, Valentin K, Weinberger F, Wiese J (2008) The genus Laminaria sensu lato: recent insights and developments. Eur J Phycol 43:1-86

Brouwer M, Lievens B, Van Hemelrijck W, Van den Ackerveken G, Cammue BP, Thomma BP (2003) Quantification of disease progression of several microbial pathogens on Arabidopsis thaliana using real-time fluorescence PCR. FEMS Microbiol Lett 228:241-248

Bustin SA, Benes V, Garson JA, Hellemans J, Huggett J, Kubista M, Mueller R, Nolan T, Pfaffl MW, Shipley GL, Vandesompele J, Wittwer CT (2009) The MIQE guidelines: Minumum information for publication of quantitative real-time PCR experiments. Clin Chem 55:611-622

Chen J (2004) Cultured aquatic species information programme. Laminaria japonica. In: FAO Fisheries and Aquaculture Department [online]. Rome. Updated 1 January 2004. [Cited 18 May 2017]

Clay K (1990) The impact of parasitic and mutualistic fungi on competitive interactions among plants. In: Grace JB, Tilman D (eds) Perspectives on plant competition. Academic Press, London, pp 391-412

Deniaud-Bouët E, Kervarec N, Michel G, Tonon T, Kloareg B, Hervé C (2014) Chemical and enzymatic fractionation of cell walls from Fucales: insights into the structure of the extracellular matrix of brown algae. Ann Bot 114:1203-1216

Eggert A, Peters AF, Küpper FC (2010) Potential impact of climate change on endophyte infections in kelp sporophytes. In: Seckbach J, Einav R, Israel A (eds) Seaweeds and their role in globally changing environment. Springer, Dordrecht, pp 139-154

Ellertsdóttir E, Peters AF (1997) High prevalence of infection by endophytic brown algae in populations of Laminaria spp. (Phaeophyceae). Mar Ecol Prog Ser 146:135-143

Gachon C, Mingam A, Charrier B (2004) Real-time PCR: what relevance to plant studies? J Exp Bot 55:1445-1454

Gachon CMM, Strittmatter M, Mueller DG, Kleinteich J, Kuepper FC (2009) Detection of differential host susceptibility to the marine oomycete pathogen Eurychasma dicksonii by real-time PCR: not all algae are equal. Appl Environ Microbiol 75:322-328

Gauna C, Parodi ER, Caceres E (2009a) The occurrence of Laminarionema elsbetiae (Phaeophyta) on Rhodymenia pseudopalmata (Rhodophyta) 
from the Patagonian coasts of Argentina: characteristics of the relationships in natural and experimental infections and morphology of the epi-endophyte in unialgal free cultures. Algae 24:249-256

Gauna MC, Parodi ER, Cáceres EJ (2009b) Epi-endophytic symbiosis between Laminariocolax aecidioides (Ectocarpales, Phaeophyceae) and Undaria pinnatifida (Laminariales, Phaeophyceae) growing on Argentinian coasts. J Appl Phycol 21:11-18

Heesch S, Peters AF (1999) Scanning electron microscopy observation of host entry by two brown algae endophytic in Laminaria saccharina (Laminariales, Phaeophyceae). Phycol Res 47:1-5

Kawai H, Tokuyama M (1995) Laminarionema elsbetiae gen. et sp. nov. (Ectocarpales, Phaeophyceae), a new endophyte in Laminaria sporophytes. Phycol Res 43:185-190

Küpper FC, Müller DG, Peters AF, Kloareg B, Potin P (2002) Oligoalginate recognition and oxidative burst play a key role in natural and induced resistance of sporophytes of Laminariales. J Chem Ecol 28:2057-2081

Lein TE, Sjotun K, Wakili S (1991) Mass-occurrence of a brown filamentous endophyte in the lamina of the kelp Laminaria hyperborea (Gunnerus) Foslie along the southwestern coast of Norway. Sarsia 76:187-193

Østgaard K, Indergaard M, Markussen S, Knutsen SH, Jensen A (1993) Carbohydrate degradation and methane production during fermentation of Laminaria saccharina (Laminariales, Phaeophyceae). J Appl Phycol 5:333-342

Peters AF (1991) Field and culture studies of Streblonema macrocystis sp. nov. (Ectocapales, Phaeophyceae) from Chile, a sexual endophyte of giant kelp. Phycologia 30:365-377

Peters AF (2003) Molecular identification, distribution and taxonomy of brown algal endophytes, with emphasis on species from Antarctica. In: Chapman ARO, Anderson RJ, Vreeland V (eds) Proceedings of the 17th International Seaweed Symposium. Oxford University Press, Oxford, pp 293-302

Peters AF, Burkhardt E (1998) Systematic position of the kelp endophyte Laminarionema elsbetiae (Ectocarpales sensu lato, Phaeophyceae) inferred from nuclear ribosomal DNA. Phycologia 37:114-120
Peters AF, Ellertsdóttir E (1996) New record of the kelp endophyte Laminarionema elsbetiae (Phaeophyceae, Ectocarpales) at Helgoland and its life history in culture. Nova Hedwigia 62:341-349

Peters AF, Schaffelke B (1996) Streblonema (Ectocarpales, Phaeophyceae) infection in the kelp Laminaria saccharina (Laminariales, Phaeophyceae) in the western Baltic. Hydrobiologia 326/327:111-116

Pfaffl MW (2004) Relative quantification. In: Tevfik Dorak M (ed) Realtime PCR. Taylor \& Francis Group, New York, pp 63-82

Potin P, Bouarab K, Salaün JP, Pohnert G, Kloareg B (2002) Biotic interactions of marine algae. Curr Opin Plant Biol 5:308-317

Provasoli L (1968) Media and prospects for the cultivation of marine algae. In: Watanabe A (ed) Cultures and collections of algae. Japanese Society of Plant Physiologists, Tokyo, pp 63-75

Rosell KG, Srivastava LM (1984) Seasonal variation in the chemical constituents of the brown algae Macrocystis integrifolia and Nereocystic luetkeana. Can J Bot 62:2229-2236

Schaffelke B, Peters AF, Reusch T (1996) Factors influencing depth distribution of soft bottom Laminaria saccharina (L.) Lamour in Kiel Fjord, Baltic Sea. Hydrobiologia 326/327:117-123

Siegel BZ, Siegel SM (1973) The chemical composition of algal cell walls. Crit Rev Microbiol 3:1-26

Thomas D, Beltrán J, Flores V, Contreras L, Bollmann E, Correa JA (2009) Laminariocolax sp. (Phaeophyceae) associated with gall developments in Lessonia nigrescens (Phaeophyceae). J Phycol 45: $1252-1258$

Wilkinson M (1995) Information review on the impact of kelp harvesting. Scottish Natural Heritage Review, No. 34

Wu C, Chen D, Li J, Jiajun L (1983) On the diseases of cultivated Laminaria japonica. In Research Report of Academia Sinica Institute of Oceanology Qingdao 763:211-221

Yoshida T, Akiyama K (1979) Streblonema (Phaeophyceae) infection in the frond of cultivated Undaria (Phaeophyceae). In: Proc. 9th Int. Seaweed Symp. Science Press, Santa Barbara, pp 213-223 